\title{
PENINGKATAN KUALITAS PEMBERDAYAAN GURU DAN MASYARAKAT UNTUK MEMINIMALISIR TERJADINYA KENAKALAN REMAJA DI DESA CIASIHAN
}

\author{
Safaruddin Hidayat ${ }^{1}$, Achmad Reza, Niya Yuliana ${ }^{2}$ \\ safaruddin@ft.uika-bogor.ac.id \\ Dosen Fakultas Teknik ${ }^{1}$, Mahasiswa KKN Kelompok 36 Tahun $2018^{2}$
}

\begin{abstract}
ABSTRAK
Desa Ciasihan adalah desa yang diapit oleh dua sungai terkenal yaitu sungai Cikuluwung dan sungai Ciasmara. Desa Ciasihan mempunyai luas wilayah 665,274 Ha, terbagi 3 Dusun, yaitu: Dusun I, Dusun II, Dusun III, dan terdiri dari 9 RW dan 52 RT, dengan jumlah penduduk sebanyak 10.536 jiwa, laki-laki 5462 jiwa dan perempuan sebanyak 5074 jiwa dari (2785 Kepala Keluarga). Banyaknya jumlah penduduk keluarga di desa Ciasihan ini, tidak dapat dipungkiri bahwa kenakalan remaja akan merajalela ke setiap desa. Perilaku menyimpang kenakalan remaja adalah suatu perbuatan yang melanggar norma, aturan, atau hukum dalam masyarakat yang dilakukan pada usia remaja atau transisi masa anak-anak ke dewasa. Kenakalan remaja merupakan kumpulan dari berbagai perilaku remaja yang tidak dapat diterima secara sosial hingga terjadi tindakan kriminal. Pada saat ini peran keluarga, guru, masyarakat serta lingkunganlah yang menjadi pondasi dan dapat membentengi agar meminimalisir terjadinya kenakalan remaja. Berpartisipasi dalam acara seminar "Mendidik anak zaman now dalam mengatasi kenakalan remaja" merupakan salah satu upaya untuk meminimalisir terjadinya kenakalan remaja di Desa ciasihan Kecamatan Pamijahan, Kabupaten Bogor
\end{abstract}

Kata Kunci : Desa Ciasihan, Guru, Kenakalan Remaja, Masyarakat, Pemberdayaan

\section{PENDAHULUAN}

Desa Ciasihan Kecamatan Pamijahan Kabupaten Bogor Provinsi Jawa Barat, merupakan 1 dari 15 (lima belas) desa di Kecamatan Pamijahan yang mempunyai jarak $60 \mathrm{Km}$ dari kota kabupaten. Desa Ciasihan adalah desa yang diapit oleh dua sungai terkenal yaitu sungai Cikuluwung dan sungai Ciasmara ini sebelumnya dikenal bernama Desa Ciasmara. Dikarenakan wilayah desa ciasmara cukup luas, maka sekitar tahun 1982 yang dahulu satu desa bernama Desa Ciasmara terjadi pemecahan atau pemekaran wilayah oleh pemerintahan daerah menjadi tiga desa yaitu desa Ciasihan, Ciasmara dan Purwabakti. Desa Ciasihan mempunyai luas wilayah 665,274 Ha, terbagi 3 Dusun, yaitu: Dusun I, Dusun II, Dusun III, dan terdiri dari 9 RW dan 52 RT, dengan jumlah penduduk sebanyak 10.536 jiwa, laki-laki 5462 jiwa dan perempuan sebanyak 5074 jiwa dari (2785 Kepala Keluarga). Secara geografis batas wilayah desa Ciasihan sebagai berikut : 


\begin{tabular}{|l|l|}
\hline \multicolumn{2}{|c|}{ Batas Wilayah } \\
\hline a. Sebelah Utara & Desa Cibitung Kulon \\
\hline b. Sebelah Selatan & Kab. Sukabumi \\
\hline c. Sebelah Timur & Desa Gunung Sari \\
\hline d. Sebelah Barat & Desa Ciasmara \\
\hline
\end{tabular}

Desa merupakan suatu wilayah pemerintahan terkecil dari suatu negara, kemajuan suatu desa akan bergantung pada kualitas sumber daya manusia didesa tersebut, terutama para remajanya yang berada di desa Ciasihan. Remaja saat ini hampir semua teridentifikasi dengan kenakalan remaja akibat dari pergaulan, Gadget, dan lain sebagainya.

Kenakalan remaja adalah perilaku jahat atau kenakalan anak-anak muda, merupakan gejala sakit (patologis) secara sosial pada anak-anak dan remaja yang disebabkan oleh pengabaian sosial, sehingga mereka mengembangkan bentuk perilaku yang menyimpang.Istilah kenakalan remaja mengacu pada suatu rentang yang luas, dari tingkah laku yang tidak dapat diterima sosial sampai pelanggaran status hingga tindak kriminal (Kartono, 2003). Sedangkan pemberdayaan menurut arti secara bahasa adalah proses, cara, perbuatan membuat berdaya, yaitu kemampuan untuk melakukan sesuatu atau kemampuan bertindak yang berupa akal, ikhtiar, upaya (Depdiknas, 2003).

Guru adalah seorang pendidik disekolah, dan sebagai seorang pendidik perlu menggunakan hasil-hasil penyelidikan psikologi dalam tugasnya, sehingga dapat memahami anak didiknya dan dapat mencari jalan keluar dalam suatu permasalahan yang dihadapi peserta didik (Haryu Islamuddin, 2014), sedangkan masyarakat adalah kesatuan hidup manusia yang berinteraksi menurut suatu sistem adat istiadat tertentu yang bersifat continue, dan yang terikat oleh suatu rasa identitas bersama (Koentjaraningrat, 2009)

Pemberdayaan Guru adalah upaya untuk meningkatkan kemampuan seorang guru pada bidangnya dalam melaksanakan fungsi dan tanggung jawabnya dilingkungan sekolah, sedangkan pemberdayaan masyarakat adalah upaya untuk memulihkan atau meningkatkan kemampuan suatu komunitas untuk mampu berbuat sesuai dengan harkat dan martabat dalam melaksanakan fungsi dan tanggung jawabnya dilingkungan masyarakat.

Peran keluarga, guru, masyarakat dan lingkungan sangatlah penting dalam proses perkembangan remaja dalam mengatasi kenakalan remaja yang marak terjadi dimasyarakat saat ini sekalipun desa terpencil. 
METODE PENGABDIAN

Adapun metode penyelenggaraannya dapat dilihat dari bagan dibawah ini :
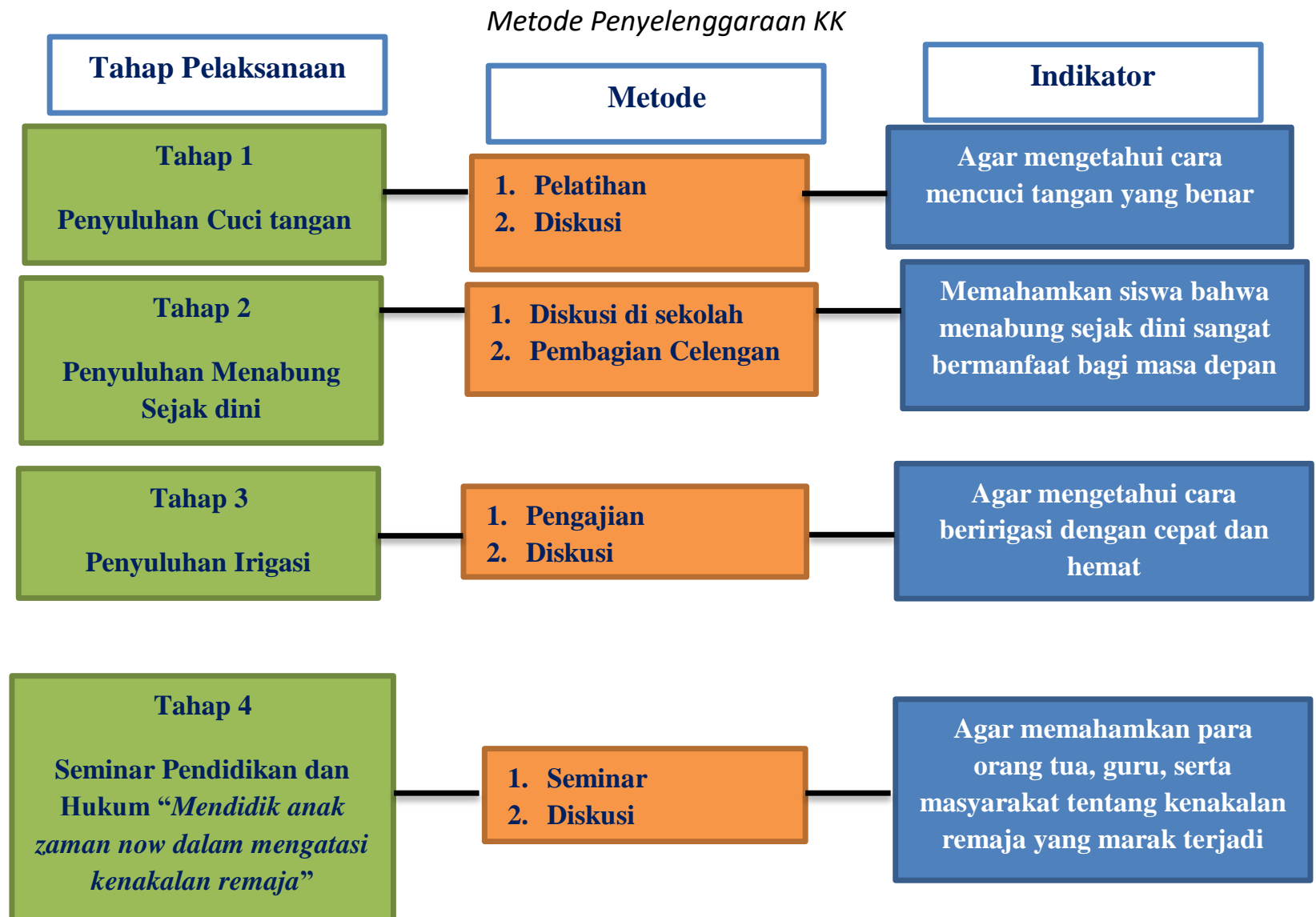

Tahap 5

Pembelajaran Les Bahasa Arab, Inggris, Matematika di Rumah Pintar
1. Majlis Ta'lim

2. Diskusi
Agar memudahkan anak anak dalam menulis maupun berbicara 
Adapun alur pelaksanaan KKN Tematik Terintegrasi 2018 kelompok 36 Universitas Ibn Khaldun yaitu sebagai berikut :



Bagan 1. Alur Pelaksanaan KKN kelompok 36 UIKA Bogor 


\section{REALISASI PROGRAM}

Dalam pelaksanaan kegiatan KKN Tematik Terintegrasi 2018 Universitas Ibn Khaldun Bogor di Desa Ciasihan Kecamatan Pamijahan Kabupaten Bogor. Alhamdulillah kami telah membuat serangkaian program kerja yang berjalan lancar. Adapun program kerja KKN Tematik Terintegrasi 2018 kelompok 36 Universitas Ibn Khaldun Bogor yang telah terealisasikan, yaitu :

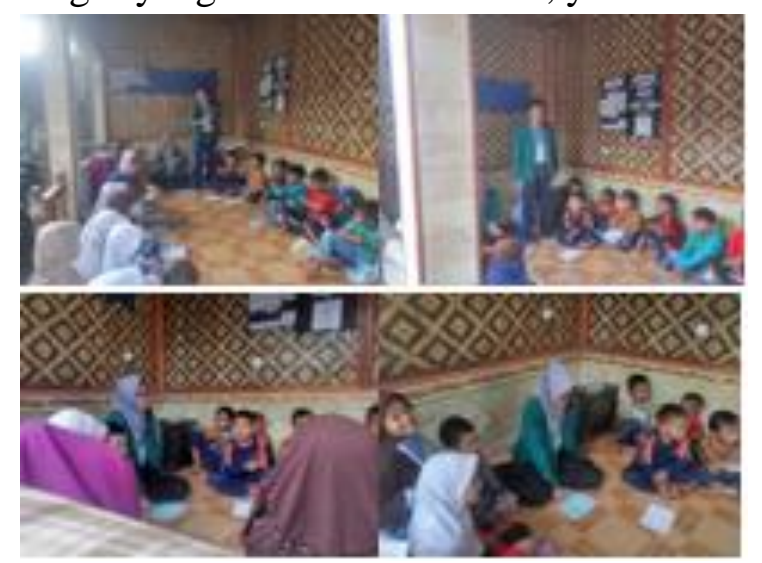

1. Penyuluhan Kesehatan (PHBS)/ Cuci tangan yang dilaksanakan pada tanggal 13 Agustus 2018 pukul 16.00 s/d 17.00 yang berlokasi tepat di posko kami.

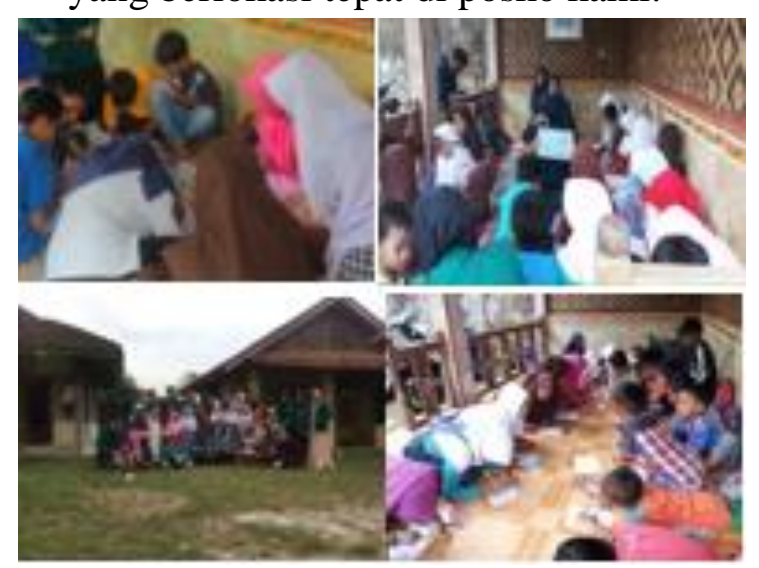

2. Program Rumah Pintar yang dilaksanakan secara rutin setiap hari Senin-Kamis pukul 16.00 WIB. Adapun pelajaran yang kami ajarkan adalah Bahasa Arab, Bahasa Inggris, dan Matematika.
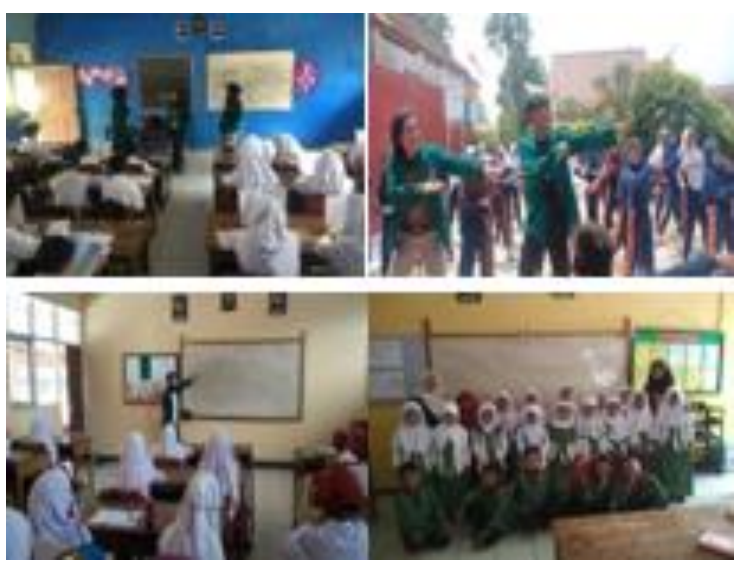

3. Kegiatan belajar mengajar di beberapa sekolah (SD, SMP, dan SMK) dengan menggunakan metode yang berbeda dan lebih menyenangkan.

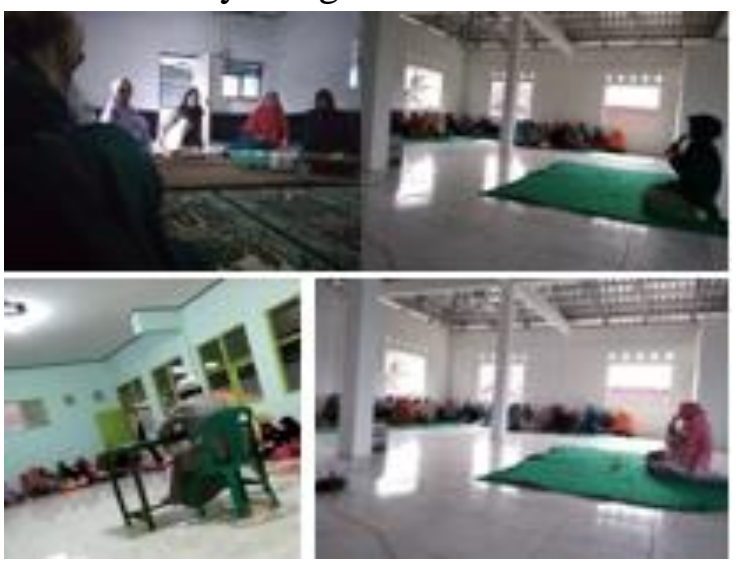

4. Pengajian Ibu-ibu yang diadakan secara rutin setiap kamis pagi dan selasa sore.

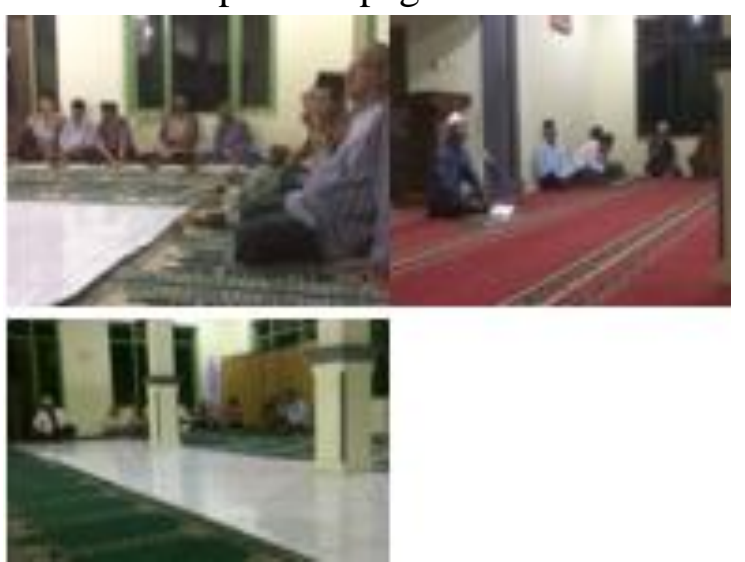

5. Pengajian Bapak-bapak yang diadakan secara rutin setiap malam minggu. 


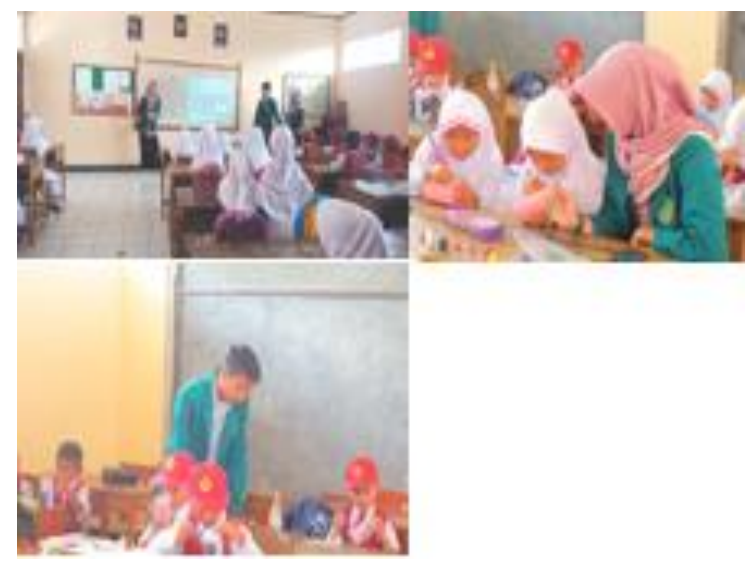

6. Sosialisasi Terhadap Pentingnya Menabung Sejak Usia Dini yang dilaksanakan pada hari Senin, 27 Agustus 2018 Pukul 07.00-09.00 di SDN Ciasihan 1 Pamijahan. Dimana kegiatan ini merupakan salah satu cara untuk menanamkan rasa gemar menabung pada anak usia dini.
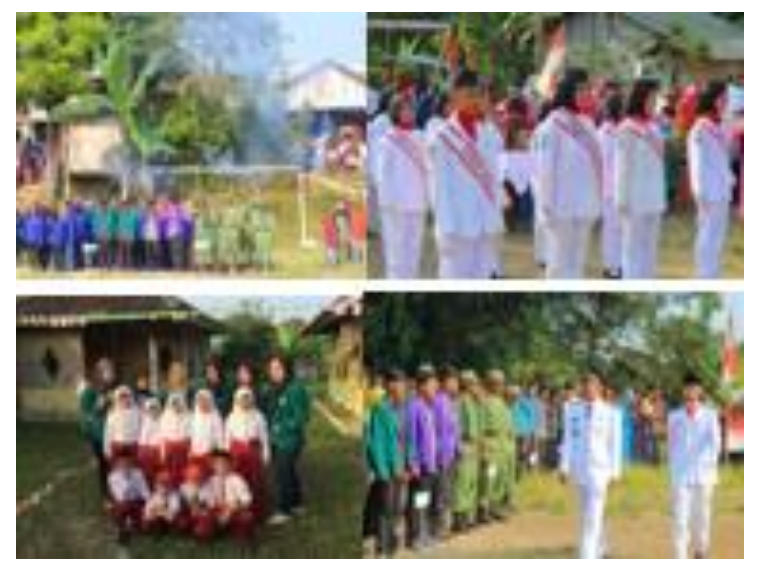

7. Upacara 17 Agustus bersama Desa di Lapangan desa Ciasihan
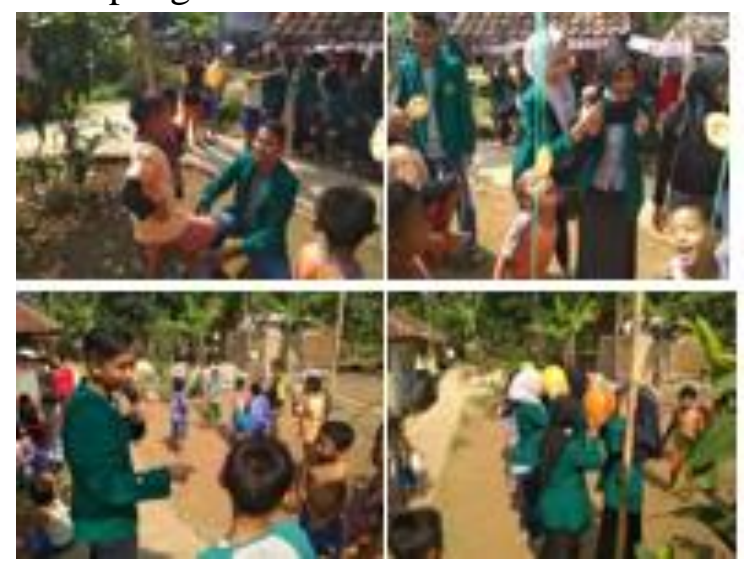

8. Ikut berpartisipasi dalam memeriahkan Lomba 17 Agustus di Tingkat RT 02 yang dilaksankan pada hari minggu, 19 Agustus 2018
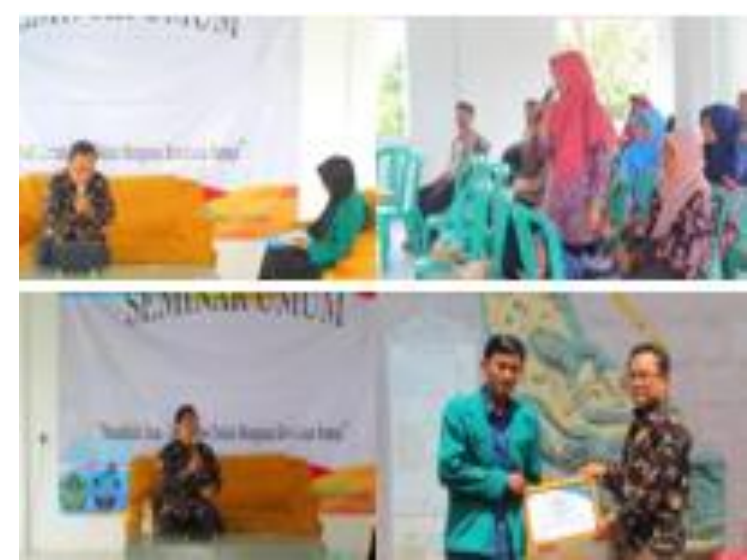

9. Seminar Umum Pendidikan dan Hukum yang diadakan di Aula Kantor Desa Ciasihan, seminar pendidikan islam ini berkolaborasi dengan bidang hukum yang bertemakan "Mendidik Anak Zaman Now dalam Mengatasi Kenakalan Remaja" oleh Pemateri Dr. M. Dahlan R., MA yang dilaksanakan pada hari Sabtu, 01 September 2018.
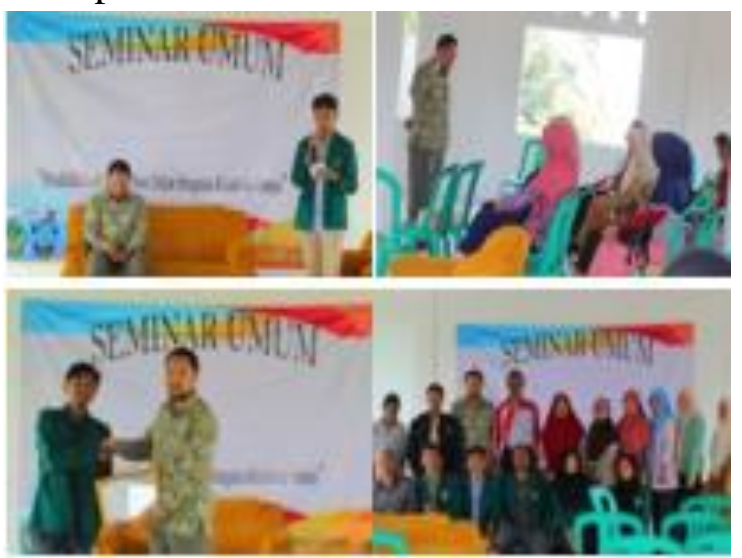

10. Dalam acara seminar umum desa Ciasihan, kami juga menjalankan program kerja pada bidang Teknologi yaitu mengenai "Penyuluhan Irigasi" oleh Pemateri Dr. Arien Heryansyah pada hari sabtu, 01 September 2018.

\section{KESIMPULAN}

Kuliah kerja nyata ( $\mathrm{KKN}$ ) pada hakekatnya merupakan perwujudan dari salah satu dharma perguruan tinggi, yakni pengabdian nyata seorang mahasiswa untuk menyalurkan potensi dan ilmunya kepada masyarakat yang sebenarnya setelah 
mendapatkan materi perkuliahan yang senantiasa dapat berguna didalam lingkungan masyarakat itu sendiri. Universitas Ibn Khaldun Bogor adalah kampus yang telah melaksanakan program KKN di 6 Kecamatan yang terbagi dalam beberapa kelompok, salah satunya adalah kelompok 36 yang bertempat di Kecamatan Pamjahan.

Alhamdulillah, segala puji syukur kami panjatkan kepada kehadirat Allah SWT, yang telah membantu dalam kelancaran dalam menyusun rencana program KKN Tematik Terintegrasi Tahun 2018 Universitas Ibn Khaldun Bogor kelompok 36 di Desa Ciasihan Kecamatan Pamijahan Kabupaten Bogor selama kurang lebih 30 hari terhitung pada tanggal 07 Agustus 2018 hingga 05 September 2018 serta ditambah dengan kegiatan surveysurvey yang dilakukan 1 minggu sebelum KKN dimulai. Rencana Program Kerja Nyata ini disusun berdasarkan dengan hasil diskusi, observasi, wawancara, serta datadata yang ada yang diharapkan dapat membantu mempermudah pelaksanaan program dan juga sebagai acuan awal bagi kegiatan dan program.

Adapun program-program yang sudah terlaksana yaitu pada bidang pendidikan, bidang kesehatan, bidang hukum, bidang lingkungan, bidang ekonomi, dan beberapa kegiatan lain setiap harinya bersama masyarakat. Ada beberapa faktor yang mendukung jalannya program KKN kelompok 36 Universitas Ibn Khaldun Bogor ini diantaranya :

1. Kerja sama antar anggota $\mathrm{KKN}$ kelompok 36 Desa Ciasihan yang sangat baik dalam menjalankan setiap program.

2. Pihak pemerintahan desa Ciasihan beserta staff jajarannya, ketua Rw, RT, dan tokoh masyarakat, dan Karang Taruna desa Ciasihan yang telah membantu memfasilitasi dalam pelaksanaan program KKN.

3. Masyarakat desa Ciasihan yang telah membantu menyelesaikan program KKN kelompok 36

Selain itu KKN 36 di Desa Ciasihan memiliki dampak bagi masyarakat. Adapun dampak bagi masyarakat seperti terbantunya anak-anak dalam menguasai bahasa asing (Bahasa Arab dan Bahasa Inggris), warga sekitar menjadi lebih akrab dan saling tolong menolong. Maka dari itu, kami mengucapkan terimakasih kepada semua pihak yang terkait yang ikut serta berpartisipasi, bekerjasama dan membantu program kerja hingga dapat terealisasikan dengan cukup baik dan bermanfaat bagi masyarakat.

\section{SARAN}

Adapun saran dari kami untuk desa yaitu :

1. Untuk pemerintahan desa, lebih diperhatikan kembali fasilitasfasilitas umum seperti lampu jalan, dan pembenahan jalan rusak yang ada di desa Ciasihan.

2. Masyarakat hendaknya harus mengerti bahwa kegiatan KKN bukan hanya untuk kepentingan mahasiswa saja, akan tetapi merupakan kepentingan masyarakat desa setempat.

3. Masyarakat harus lebih antusias dan berperan aktif dalam membantu kegiatan mahasiswa KKN kelompok 36 di desa Ciasihan. 
Volume 02 Nomor 03, September 2018

\section{REFERENSI}

Administrasi Profil Desa Ciasihan

Erie Khutbawanti, Yoan Tricylia Dewi \& Eko Taris Wicaksono. Dinamika Kenakalan Remaja Pada Siswa Sekolah Menengah Pertama Darul Ihsan Muhammadiyah Sragen [Di Akses Sep 15 2018].

Petunjuk Pelaksanaan KKN Tematik Terintegrasi 2018, LPPM UIKA BOGOR 2018, UIKA Press

Rahelia Barande, Peran Tokoh masyarakat menanggulangi kenakalan remaja toraja di Kelurahan Maluang Kabupaten Berau, ejournal SosiatriSosiologi, Volume 6, Nomor 1, 2018 [Di Akses Sep 15 2018]. 